\title{
LAZER E RELIGIÃO: CONTEXTOS DA ATUAÇÃO DE LÍDERES RELIGIOSOS COMO MEDIADORES DO LAZER
}

\section{LEISURE AND RELIGIOUS GROUPS: CONTEXTS IN THE PERFORMANCE OF RELIGIOUS LEADERS AS MEDIATORS OF LEISURE}

\author{
Cathia Alves* \\ André Henrique Chabaribery Capi ${ }^{* *}$
}

\begin{abstract}
RESUMO
Com o objetivo de trazer à tona reflexões sobre a formação e atuação profissional no lazer, recorremos ao vínculo entre o campo do lazer e a ação de líderes religiosos (de cunho cristão) que tem em suas igrejas a possibilidade de desenvolvimento de processos formativos que influenciam diretamente a atuação posterior como educadores e ou profissionais do lazer. Estabelecemos para a discussão uma revisão da literatura em torno dos textos que incorporam essas temáticas, tais como artigos, dissertações e teses. Desse modo, identificamos um caráter de combinação, ou seja, mistura e associação entre o campo do lazer e os aspectos religiosos que refletem na formação de um profissional do lazer. As vivências de liderança de atividades e ações no contexto das igrejas colaboram para a composição de um arcabouço de conhecimentos que contribuem no processo formativo de profissionais do lazer.
\end{abstract}

Palavras-chave: lazer, religião, formação e atuação.

\begin{abstract}
With the aim of bringing to light reflections on professional formation and professional activity in leisure, we have recourse to the link between the field of leisure and the action of religious leaders (of a Christian nature) who have in their churches the possibility of developing formative processes that influence Directly as educators and / or leisure professionals. We have established for the discussion a review of the literature around the texts that incorporate the topic in vogue, such as articles, dissertations and theses. In this way, it was possible to identify a combination character, that is, a mixture and association between the field of leisure and the religious aspects that reflect in the formation of a leisure professional. The leadership experiences of activities and actions in the context of the churches collaborate to the composition of a knowledge framework that contribute in the formative process of leisure professionals.
\end{abstract}

Keywords: Leisure, religion, formation and acting.

\footnotetext{
* Doutora em Estudos do Lazer (EEFFTO/UFMG). Professora do Instituto Federal de São Paulo - campus Salto, IFSP - SP. Integrante do Oricolé - Laboratório de Pesquisa sobre Formação e Atuação Profissional no Lazer da UFMG. Integrante do grupo de pesquisa LIMC - Grupo Multidisciplinar de Estudos de Linguagens e Manifestações Culturais do IFSP - campus Salto. alves.cathia10@gmail.com

" Doutor em Estudos do Lazer (EEFFTO/UFMG). Professor Universidade de Araraquara (UNIARA) e UNIP (Campus Araraquara - SP). Integrante do Oricolé - Laboratório de Pesquisa sobre Formação e Atuação Profissional no Lazer da UFMG. Professor de Educação Física Ensino Fundamental da rede Municipal de Araraquara-SP. andrechacapi@gmail.com
} 


\section{INTRODUÇÃO}

A conjuntura de grupos religiosos, de tradição cristã, e o lazer demonstram ao longo do tempo muitas aproximações, entre elas, a busca da socialização e sociabilidade das pessoas, em suas atividades. A recreação e a vivência do lazer com grupos religiosos cresceram nos últimos anos, pois muitos grupos estão organizados por ministérios e lideranças que atuam na perspectiva da comunhão, congregação e formação de comunidades (ALVES, 2010).

A definição dos grupos religiosos cristãos que se tornaram objeto dessa investigação teve como critério de escolha as religiões mais hegemônicas praticadas no Brasil, considerando os resultados do Censo Demográfico 2010 (CENSO DEMOGRÁFICO, $2010)^{1}$ e a acessibilidade dos pesquisadores há dois desses grupos (católicos e evangélicos). Devido o pluralismo religioso no Brasil e dos significados múltiplos entre os termos religião, religioso e religiosidade, no qual a sua compreensão opera em planos diversos da vida social, optamos por abordar o termo religião, compreendendo-o como "uma perspectiva (um modo de ver), uma organização cognitiva do mundo, entre outras possíveis (senso comum, ciência e estética), expressa em práticas e em um conjunto de símbolos que dão sentido à existência e aliviam o sofrimento". (ALMEIDA, 2004, p. 18)

A partir disso compreendemos que o lazer no âmbito religioso, associado ao elemento lúdico, tornou-se um dispositivo de evangelismo, um mecanismo que atrai e distrai as pessoas em comunidades, aproximando e contribuindo para diferentes formas de conviver e cultuar desses grupos. Entendemos que investigar a relação entre lazer e religião e suas implicações na formação profissional é uma oportunidade para compreender como o acesso às experiências, informações, conhecimentos e formas de organização manifestadas no contexto da religião pode influenciar na construção de saberes sobre lazer e, consequentemente, na formação e atuação profissional desse campo.

\footnotetext{
${ }^{1}$ Adaptado do Gráfico 37 - Percentual da população residente, segundo os grupos de religião Brasil - 2000/2010 (CENSO DEMOGRÁFICO, 2010, p. 91): Católica/Apostólica/Romana - 64,6\%; Evangélica - 22,2\%; Espírita - 2,0\%; Umbanda e Candomblé - 0,3\%; outras religiosidades - 2,7\%; sem religião - 8,0\%. Disponível em: <http://biblioteca.ibge.gov.br/visualizacao/periodicos/94/cd_2010_religiao_deficiencia.pdf >. Acesso em: 10 mai. 2017.
}

Deste modo, buscamos nesta investigação bibliográfica apresentar os aspectos que vinculam o lazer e a religião, como também, identificar como as experiências nos espaços religiosos contribuem na formação e atuação de profissionais do lazer. Para o levantamento bibliográfico, realizado no google acadêmico e periódicos eletrônicos, selecionamos textos, artigos, dissertações e teses que contemplam a temática da religião e lazer; líderes religiosos e lazer.

A temática lazer, formação e atuação profissional vêm sendo examinada em muitos estudos e têm proliferado um conjunto de saberes e conhecimentos em torno de processos interventivos, abordando a formação profissional em lazer de nível médio e universitário e a atuação com diversas faixas etárias e diferentes ambientes (CAPI, 2016; ALVES, 2007; ISAYAMA, 2002, 2003, 2004, 2005, 2009, 2010, 2013; MARCELLINO, 2001a, b, 2003; MELO; ALVES JUNIOR, 2012; MELO, 2010, 2011a, 2011b, 2013; PINTO, 2001; SANTOS; ISAYAMA, 2014; UNGHERI, 2014; WERNECK, 1998, 2000).

No contexto desse estudo, compreendemos o lazer como dimensão da cultura, direito social e necessidade humana atrelada aos valores que essa expressão dissemina. Vale ressaltar que o lazer não possui uma única caracterização, apresenta-se como um componente repleto de variação, o que possibilita interações que vão desde o âmbito social à educação; relações com o tempo, com atividades recreativas e exerce um papel educativo representativo e ainda; está associado aos processos de subjetivação dos sujeitos e ao contexto histórico, social e econômico.

\section{APROXIMAÇÕES: OS GRUPOS RELIGIOSOS CRISTÃOS E O LAZER}

O estudo de Requixa (1977), que relata sobre o elemento lúdico nas etnias formadoras da nacionalidade brasileira, destaca os aspectos religiosos entre a igreja católica e protestante. Comportamentos relacionados aos prazeres foram controlados e considerados como atitudes pecaminosas, entretanto, no Brasil a Festa de São Gonçalo² (portuguesa) e as danças das

\footnotetext{
${ }^{2} \mathrm{~A}$ festa celebra um santo português, sugerindo uma relação do santo com a identidade nacional, o que se distingue do fato de São Gonçalo ter nascido em Portugal, falecendo a 10 de janeiro em Amarante. A festa de São Gonçalo é oficialmente celebrada a cada 10 de janeiro, desde o século XVI [do latim janua, "porta"], e, nesse sentido, tem a particularidade de conservar aspectos dos rituais que assinalam um tempo de renovação. A festa que coincide pela via
} 
festividades religiosas dos negros se fundiram e adentraram o campo religioso brasileiro, rompendo em manifestações lúdicas ligadas ao âmbito religioso.

$\mathrm{Na}$ igreja dos mórmons, por exemplo, ocorre a valorização dos aspectos saudáveis das atividades físicas e recreativas, entendendo que nessas práticas ocorre a valorização das brincadeiras e alegrias, repudiando comportamentos severos, com o propósito de “espiritualizar a recreação" (PARKER, 1978, p. 126).

As diferentes religiões cristãs manifestam nas suas festas o vínculo com o sagrado ou profano. Segundo Rosa (2002) a festa é associada a motivações, valores e interesses diversos relacionados à agricultura, à gastronomia, ao folclore, ao trabalho e à religião.

Nas igrejas católicas, evangélicas e mórmons as festas ocorrem em datas e períodos para a celebração da páscoa, festa junina, natal, entre outras, que permite vincular a religião ao lazer. Rosa (2002) destaca que as festas são momentos que denotam a pluralidade das motivações, valores e interesses que cercam as práticas festivas, suas interfaces, bem como a interrelação desses elementos com a vida cotidiana de uma população e de um local. Para Rosa (2002, p. 19)

Ao manifestar-se como tempo e espaço de vivência do lazer, a festa desvela, dentre outros aspectos essenciais, a interdependência lazer e trabalho, mostrando que as diversas facetas da vida humana não estão separadas.

A associação entre festa e religião cristã é um fato histórico que representa a união de várias esferas da vida humana num único momento. As festas religiosas nessas igrejas são representações de lazer de muitos povos e comunidades, propiciando possibilidades de expressão do lúdico.

Requixa (1997, p. 36) afirma que perdura cada vez mais o elo entre religião e lúdico, quando afirma que: "O dia de finados é um acontecimento social". Segundo o autor as pessoas nessa data, marcam de se encontrar, vestem roupas boas, se arrumam, vivencia-se aspectos sociais de caráter sincrético recreativo e religioso, características que permanecem até os dias de hoje. Baseado no texto de Maria Isaura Pereira Queiroz de 1973, Requixa (1977) destaca que as festas

\footnotetext{
do calendário com a "festa de Jano", evoca o Deus romano que é representado com dois rostos que se opõem, um olhando para a frente e outro olhando para trás (SANTOS, 2003).
}

religiosas cristãs são atividades de culto e de recreação porque envolvem dimensões sociais, recreativas, festivas e congregacionais.

$\mathrm{Na}$ atualidade as igrejas cristãs (evangélica e católica) promovem festas associadas a campanhas para arrecadação de fundos missionários e ou eventos festivos que marcam determinado período do ano, como "festa do milho", "jantar a fantasia", "feira missionária", "jantar de réveillon", entre outras atividades que possuem características de diversão, doação, comunhão e irmandade que perpassam pela ludicidade.

Parker (1978) afirma que lazer e religião identificam-se historicamente, em função da existência nos dois campos de características como bem-estar, prazer, integração e valorização das relações entre as pessoas. "O lazer tem diversas afinidades com a religião: ambos expressam o desejo de bem-estar pessoal, proporcionam oportunidades para o exercício do livre arbítrio, são integradores e abrangentes e dão significado especial a re-criação (recreação)" (PARKER, 1978 p. 124).

Para Parker (1978) e Alves (2010) o tipo de crença influencia as oportunidades de lazer de muitos fieis. As práticas religiosas exercem um papel pedagógico e político de influenciar e promover atividades e opções de lazer, entre as comunidades, predominando um alcance maior entre crianças, adolescentes e jovens.

Dessa forma, os grupos religiosos se identificam pelas suas crenças. Geralmente são movidos pela fé em uma força sobrenatural, referem-se aquilo que é sagrado em atitude de obediência, submissão e adoração; podem se diferenciar pelas suas doutrinas e rituais, que nas religiões cristãs, caracterizam-se como igrejas, paróquias, templos, grupos, etc. (ALVES, 2010).

Segundo Alves (2010) numa outra esfera percebemos a exacerbação ao extremo da devoção a Deus, instrumentalizando os momentos de lazer e ludicidade para alienar e conformar as pessoas a se adequarem e permanecerem obedientes e submissas, utilizando do lazer para pregarem os valores do seu grupo religioso, fazendo com que deixem de lado suas vidas, suas famílias, seu grupo de amigos, muitas vezes até a profissão, priorizando a prática e a obrigação religiosa, associando o lazer ao cumprimento de regras e disciplinas religiosas. As duas esferas têm o lazer como dispositivo de servir e adorar a Deus, e suas práticas 
associam-se aos valores dessas religiões cristãs e as buscas individuais de cada sujeito.

O que nos parece é que toda atividade de lazer neste ambiente é permeada pelas obrigações religiosas, o lazer se torna mecanismo de crescimento espiritual e permanência na comunidade (ALVES, 2010).

Para Gabriel (2008), a relação do lazer com o ambiente da igreja, ou com as questões de religião, representam uma temática delicada, haja vista que ambos os campos são rodeados de preconceitos e mal-entendidos. O autor indica que, ainda que a intenção da igreja não seja de experimentar os valores do lazer, ela estabeleceu resistência e oposição às exigências de trabalho movidas pelos atributos do capital, entretanto, "essa resistência não durou muito em virtude dos próprios interesses eclesiásticos nos frutos do desenvolvimento, advindo do trabalho da sociedade capitalista moderna" (GABRIEL, 2008, p. 65).

Dessa forma, a igreja acabou por incorporar os valores do capital e sucumbiu às exigências do tempo do trabalho. Contudo, Alves (2010) aponta que o lazer e a religião se identificam pela busca da socialização e sociabilidade das pessoas. O lazer, nos ambientes das igrejas, sofre a ação dos valores da religião de acordo com as características da mesma; ou seja, a partir da doutrina e organização funcional as vivências de lazer são desenhadas e configuram-se nos moldes de normatização da determinada religião.

A pesquisa de Gabriel e Vieira (2001), indicam que com relação às práticas de lazer de um grupo de adolescentes de uma comunidade cristã protestante, há evidência da influência da igreja, pois a maioria do grupo vivência as práticas sociais e culturais em companhia de amigos da igreja. Outras atividades como os passeios, práticas esportivas, os grupos de dança, música e coral, representam práticas de lazer e ocupação do tempo livre, uma vez que são vivenciados nos espaços religiosos cristãos com aspectos de atitude de espontaneidade e de prazer elevados, características essenciais do lazer.

Um dos exemplos de destaque de práticas de lazer que coaduna com os valores da religião, é o acampamento, eleito como um momento peculiar no aspecto motivacional dos aprendizados dos valores transmitidos por determinadas denominações protestantes (GABRIEL; VIEIRA, 2001).

Os feriados religiosos como, natal, páscoa, dias de santos, entre outros, também se remetem à proximidade entre lazer e religião e colaboram para a associação desses elementos por meio de expressões ligadas às artes e ao lúdico, como as encenações teatrais, letras de músicas e danças.

Ao tomar o lazer como dispositivo pedagógico de evangelismo, compreendemos que é um meio que distrai as pessoas de suas obrigações, atrai e chama a atenção daqueles que estavam distantes de suas crenças; ou ainda, é um dos fatores determinantes para se escolher uma religião, pois quando as atividades de lazer que aquele grupo religioso proporciona são prazerosas, criativas e divertidas, as pessoas têm mais vontade em querer participar (ALVES, 2010).

Gabriel e Vieira (2001) apontam que na linha protestante, a Escola Bíblica Dominical (estudos bíblicos aos domingos pela manhã, seriado em grupos por faixas etárias ou interesses); o Culto de domingo a noite (que posteriormente leva para o encontro social); os Cultos da mocidade (encontro de jovens geralmente aos sábados a noite); Discipulados ou Células (encontros semanais na igreja ou na casa de um dos integrantes da igreja para estudos bíblicos); são momentos que demonstram preocupação concernente à utilização de práticas lúdicas que colaborem para o crescimento espiritual dos membros e para formação de valores morais e espirituais, como relacionamentos, aprendizagem e comunicação.

Assim, o componente lúdico presente em ambas as esferas também é considerado elemento que atrai e associa esses campos. Segundo Parker (1978) há inúmeras tentativas de aproximar e "reconciliar" o espírito lúdico, o lazer e a religião.

O componente lúdico da cultura, fator que atrai às pessoas a prática religiosa, está cada vez mais ligado e amalgamado às obrigações e ao lazer do ambiente religioso. Caracteriza-se como uma expressão de alegria, liberdade e júbilo, manifesta-se, nos momentos de culto, missa, reuniões; através das músicas, (hinos, cânticos, corinhos, hinetos), da comunhão entre os irmãos, das orações, dos teatros, das palmas, enfim, da expressão corporal como um todo. Se expressa também, privilegiadamente nos momentos de lazer, em encontros, reuniões, acampamentos, escola bíblica de férias, ações comunitárias, eventos esportivos, etc.; atividades que também cresceram nesse meio, para envolver mais os irmãos e membros de tal comunidade (ALVES, 2010). 
Segundo Gomes (2014) o lazer é composto pela necessidade de fruição lúdica e se forma por práticas sociais constituídas culturalmente. Essa instância é concretizada a partir de valores e interesses, contextualizados de forma histórica, social e cultural pela diversidade de sujeitos.

Reconhecendo o fundamento do lúdico na cultura, é essencial sua vivência e seu experimento diário. É possível vivenciar a ludicidade no lazer como um espaço privilegiado (MARCELLINO, 2005; 2008a), com valores que nem sempre podemos vivenciar no cotidiano, realçando sua importância cultural, como elemento fundante da cultura, de uma perspectiva antropológica (HUIZINGA, 1986) ou psicanalítica (WINICCOTT, 1975).

Desse modo, o lúdico é compreendido como expressão de alegria, tensão, prazer, relaxamento que pode ocorrer em qualquer tempo, sem restrição especifica de uma única atividade, encontrando no lazer formas favorecidas de se manifestar. No jogo, brincadeira e brinquedo se assemelha historicamente e tem sua conceituação quase que como sinônimo destas atividades (ALVES, et. al., 2014).

Para Gomes (2014) a palavra ludicidade, ainda que associada historicamente a infância e tratada como sinônimo de jogo pode ser ampliada no momento que considerarmos que a construção lúdica se dá a partir das experiências vividas pelos sujeitos interagindo com o lúdico.

Camargo (2016) ao abordar especificamente a passagem da cultura tradicional para a modernidade na sociedade brasileira conclui que a característica lúdica é um patrimônio cultural devido à herança das marcas rurais e tradicionais.

Assim nesse processo do lazer ligado ao lúdico, podemos citar que essa fruição no seguimento religioso se representa por duas esferas, a primeira delas, abrange as formas de estreitar os laços entre os irmãos, buscando comunhão, convivência, ajuda mútua, trocas de experiência; tem o objetivo de se formar uma "família" entre aqueles participantes que comungam a mesma fé, pregam os mandamentos bíblicos e associam as atividades de lazer com contextos e textos da bíblia. Preocupam-se com o próximo, com o testemunho, não se privam do descanso e da diversão, baseiam-se no texto em que "tudo me é lícito, mas nem tudo me convém”. O cumprimento das ordenanças é seguido e doutrinado nos momentos de lazer (ALVES, 2010).

Numa segunda esfera, identificamos as ações e atividades de lazer ofertadas pelas igrejas que procuram disseminar uma comunidade que coopera com as mudanças e processos de inclusão social, voluntariado, respeito as diferenças, reflexões sobre o sagrado e o profano, num contexto de se posicionar como um local que aceita e respeita as diferentes formas de ser humano. O lazer ofertado procura se modernizar e desloca-se para atrativos e recreações que imprimam movimentos diferenciados, têm como objetivo despertar e atrair a atenção das pessoas para que participem e se sintam parte do grupo. As duas esferas estão disseminadas, espalhadas e operam nas igrejas e grupos religiosos sem distinções.

Contudo lazer e religião cristã, permeados pelas expressões lúdicas expressam bem-estar e realização pessoal; são oportunidades de livre arbítrio, mas ao mesmo tempo, são restritivas; promovem uma sensação de paz e de alegria; recreação e comunhão, fortalecem a fé e a igreja (PARKER, 1978; ALVES, 2010).

\section{OS LÍDERES RELIGIOSOS E OS REFLEXOS NO CAMPO DO LAZER}

$\mathrm{Na}$ atualidade, os estudos sobre formação na área do lazer buscam diálogos com outras áreas, como a educação e os estudos culturais, para avançar na produção de conhecimento que possa contribuir nas intervenções do profissional e, na construção do conhecimento acerca da temática. Essas buscas propiciam a oportunidade de qualificação dos profissionais de lazer, a fim de entender e apontar o papel do eixo da formação em diferentes espaços e momentos e, como ela pode contribuir nesse processo.

A relação de profissionalismo é tensa no lazer, pois, por ser um campo do conhecimento da cultura, do esporte, do turismo, da educação, sociologia, psicologia e outros; ou seja, multidisciplinar (ISAYAMA, 2005; 2009; 2010; 2013) não tem uma formação e uma profissionalização com uma única especificidade, gerando a possibilidade de diferentes profissionais atuarem. Dialeticamente, provoca-se um movimento que produz um processo carente na formação e profissionalização daqueles que atuam em tal campo, o que pode gerar um desconforto e um desconhecimento 
profissional, ou seja, atuar no lazer não é oficio e nem puramente uma profissão.

É necessário compreender que o campo necessita de um profissional que tenha clareza e domínio de sua especificidade em sua área ou esfera de conhecimento.

Por reconhecer essa característica multidisciplinar do lazer, Isayama (2013) atenta para uma organização de formação interdisciplinar. Lembrando que ainda existem preconceitos e limitações no campo com visões arbitrárias que desconsideram a formação específica do profissional do lazer.

O estudo de Isayama (2010) aponta que a busca pela qualificação da formação do profissional do lazer, no país, concretiza-se, principalmente, por duas perspectivas. Uma que tem a técnica como fio condutor, cuja preocupação é formar um profissional mais técnico que tem como orientação primordial o domínio dos conteúdos específicos, metodologias e privilegia a familiarização com as práticas e atividades que se apresentam no dia a dia do animador cultural. A outra perspectiva entende que a formação deve centrar-se no conhecimento, na cultura e na crítica, que se dá por meio "da construção de saberes e competências que devem estar alicerçados no comprometimento com os valores disseminados numa sociedade democrática, bem como na compreensão do papel social do profissional na educação para e pelo lazer" (ISAYAMA, 2010, p. 13).

Nesse estudo corroboramos com essa segunda perspectiva, portanto, ao trazermos para o debate a formação, a religião e o lazer compreendemos essa tríade como uma possibilidade para o rompimento com a visão tecnicista, comum em nosso meio. Buscamos nas experiências das atividades de lazer vivenciadas no âmbito da religião perceber se as práticas são conscientes, pautadas na competência técnica, científica, política, filosófica e pedagógica e no conhecimento crítico da realidade.

Isayama (2005) chama a atenção para o fato de que a experiência por si só, não demonstra conhecimento, mesmo porque a prática muitas vezes pode diminuir a teoria na ação profissional. Nesse sentido um profissional experiente não pode se desvincular do processo de formação, é preciso renovar e afirmar seu conhecimento, ampliando as possibilidades de ação, partindo da cultura da comunidade e de sua criatividade, conectado as esferas interiores e exteriores. Mas como problematizar essa questão da ação e mediação no lazer quando relacionado às intervenções realizadas no âmbito dos grupos religiosos?

Segundo Ramos (2011) a religião desempenha um papel político e ideológico, pois é permeada de contradições e, também, porque cria em seu meio intelectuais que fornecem interpretações não somente doutrinárias, mas de mundo e de sociedade. Assim, justificamos a importância de trazer à tona os vínculos que se formam entre lazer e religião.

Consideramos que a aproximação entre lazer e os grupos religiosos é histórica, e nessa relação há um personagem que contribui para essa ligação, o líder religioso. O líder religioso tem disponibilidade para liderar, organizar e se responsabilizar por um determinado ministério, sessão ou área dentro da igreja. Geralmente é membro daquela comunidade, é frequente aos cultos e participa das demais atividades da comunidade religiosa, é envolvido e conhecido por muitos irmãos. O líder pode ser jovem ou adulto, do sexo masculino ou feminino, que se constitui como o sujeito que toma para si a responsabilidade de promover, elaborar, organizar e controlar as ações de lazer na esfera da igreja.

Em um grupo religioso podem ser fabricados diversos líderes, de acordo com a faixa etária (crianças, adolescentes, jovens, pessoas idosas); ou pode ser referente a características sociais, como o grupo dos casados, o grupo de mulheres, homens, pessoas idosas, entre outros. E, além disso, a fruição desses líderes pode ser organizada por meio de ministérios ou sessões, e assim cada uma dessas categorias tem seus líderes que geralmente estão subjugados a um apóstolo, diácono, pastor ou padre.

Nessa configuração o líder é o mediador das atividades nesses grupos religiosos e ao longo do processo de participação e envolvimento apreende conhecimentos relacionados ao lazer, como organizações de eventos e festas, aplicação de jogos, brincadeiras e atividades esportivas, portanto, é a personagem que constrói saberes, competências e produz os lazeres nos ambientes das igrejas cristãs.

Soares (2009) ao investigar a relação do lazer com os hábitos de líderes religiosos identificou que as práticas de um grupo de freiras se parecem com as de um grupo de líderes evangélicos, entretanto, o nível de instrução das mulheres evangélicas é superior ao dos homens da mesma religião e o grupo 
de padres apresentam alto índice de escolaridade e instrução. O estudo foi realizado por uma amostra, do tipo intencional, que totalizou 112 entrevistados (23 padres, 49 freiras, 31 pastores e 9 pastoras). Quando questionados sobre as atividades de lazer preferidas, as mais citadas pelos padres foram às atividades sociais (encontro com amigos e família, viagens e passeios). Dentre as freiras as atividades que mais se destacaram foram as intelectuais e manuais (leituras e artesanatos); já entre os líderes evangélicos a maioria dos pastores relataram ter preferência por atividades físicas e ao ar livre nos momentos de lazer, entretanto, complementaram que as praticam pouco. As pastoras disseram que optam pelas atividades intelectuais - a leitura, palavras cruzadas, estudos e jogos de computador (SOARES, 2009).

Conforme destacam os estudos de Marcellino (2008b) e Alves (2013) esse cenário observado na pesquisa com líderes religiosos não difere dos resultados do público em geral que também demonstram que geralmente o querer não representa o fazer das pessoas quanto aos seus lazeres.

No contexto da atuação profissional, o estudo de Alves (2017) destaca que a experiência anterior, na esfera da igreja cristã, de quatro mediadores de atividades de lazer num Programa de política pública educacional, propiciou a criação de repertório de cunho artístico, autonomia para elaboração, imaginação, cópia e invenção das atividades e produtos. Os sujeitos educadores são regrados e disciplinados, fundamentam suas práticas num contexto de ensino-aprendizagem, operando com processos que objetivem uma instrução específica para elaboração de um produto final, consultam a internet para ter ideias, copiar e inventar suas práticas.

Os sujeitos relataram que o fato de mediar as atividades de contar histórias, montar coreografias, fazer teatro com as crianças, ensinar artesanatos para as mulheres, organizar eventos, cooperou para que aprendessem sobre lazer e tivessem facilidade para atuar num Programa de política educacional que opera intersetorialmente com o lazer (ALVES, 2017).

O estudo de Capi (2016) identificou que alguns profissionais do lazer que atuam como formadores de agentes sociais de um Programa social de esporte e lazer de âmbito nacional também consideraram as experiências vivenciadas nas atividades da igreja, na juventude, como processos formativos para aguçar seu interesse em ampliar o repertório de jogos e brincadeiras e o acesso aos conteúdos artísticos (música, cinema, teatro). Esses profissionais destacaram que o processo de planejamento, organização e execução das atividades recreativas com o grupo de jovens permitiu compreender o papel do voluntariado nas ações do lazer.

Portanto, as vivências e experiências de lazer no âmbito religioso têm proporcionado a aprendizagem de valores de organização, repertório de atividades recreativas, criatividade, espontaneidade, trabalho coletivo e auto-organização como componentes que contribuem na formação profissional de um mediador nas práticas de lazer que atua em outros campos.

O profissional que atua no campo religioso precisa programar atividades que englobem a comunhão, o ensino sobre os valores daquela determinada religião e ao mesmo tempo promover possibilidades para as pessoas se divertirem, descansarem e desenvolverem uma consciência em relação as suas crenças e atitudes. Na maioria das vezes as práticas de lazer se restringem a atividades que envolvem o uso da bíblia ou ações que tragam uma mensagem de adoração e devoção a Deus (ALVES, 2010). É possível fazer uso de diferentes atividades abrangendo vários conteúdos do lazer, sem perder de vista os objetivos da religião específica, mas que também não descaracterize a espontaneidade e o caráter lúdico das vivências de lazer.

Outro aspecto que chama a atenção é de que se faz necessário conhecer a história do determinado seguimento religioso, para que o líder (profissional, animador, educador, mediador) aja de acordo com os valores e características do mesmo. A atuação do líder, mesmo considerando esses aspectos do grupo, deve abrir possibilidade para a problematização e questionamento da realidade, possibilitando às pessoas reconhecerem o tempo de lazer como um momento de construção de saberes que podem contribuir com o enfrentamento de situações do cotidiano com atitude de confiança e responsabilidade, afim de superar as diferentes barreiras que se manifestam de múltiplas formas em contextos complexos e diversificados na vida social, profissional, religiosa e de lazer.

Para atuar nessa perspectiva o mediador, além da boa vontade e disposição, precisa ser alguém preparado e competente para planejar, executar e avaliar as programações. É indicado também que ele não reduza o lazer a único conteúdo cultural, ou mantenha o lazer 
na religião ligado somente às obrigações religiosas, mas deve valer-se da capacidade de superação do grupo, alcançando todas as possibilidades de vivências. E ainda fazer com que o lazer seja operado de forma espontânea, promovendo um desenvolvimento individual; consciente dos principais valores que a comunidade tenta alcançar: a comunhão, o respeito, a cumplicidade e o sentimento verdadeiro de irmãos uns pelos outros, e também momento de diversão e descanso (ALVES, 2010).

Realizar um empenho educativo de não ser um profissional que impõe preceitos e disciplina para o lazer e ao mesmo tempo, instruir e informar. A partir dos conhecimentos apresentados e daqueles que já possui, contribuir para que o sujeito faça suas escolhas (QUEIROZ, CHAVES e ALVES, 2016).

Acreditamos no movimento das intervenções e nas alterações e modificações das vivências e experiências de lazer associadas a determinados períodos históricos e contextos. É importante que o animador (líder, mediador, educador) verifique seu lugar, sua situação e olhe para o outro, respeitando as diferenças e características locais para realizar as mediações e os processos de intervenção de forma educativa (QUEIROZ, CHAVES e ALVES, 2016).

\section{CONSIDERAÇÕES FINAIS}

Ao lançar o desafio de analisar a atuação dos líderes religiosos no desenvolvimento das atividades de lazer nas igrejas cristãs como um momento construção de saberes identificamos que os processos de formação são determinantes para caracterizar a ação profissional dos educadores de lazer, bem como, um conjunto de saberes e conhecimentos acumulados e adquiridos, junto as suas particularidades, tais como sensibilidades e experiências pessoais, culturais e sociais. Nesse sentido compreender as possibilidades de articulação entre as atividades de lazer no contexto das estratégias de intervenção da religião cristã permitiu identificarmos a concretização da mediação de atividades na esfera da igreja como um ambiente, momento e experiência a serem consideradas como parte do processo formativo para atuação no campo do lazer.

Concluímos, sem esgotar a temática, que a formação consistente e de desenvolvimento de competências e habilidades técnicas, culturais, pedagógicas e políticas podem possibilitar uma atuação no campo do lazer com maior eficácia, associando o caráter político de intervenção e melhora das condições de vida das pessoas.

Dessa forma, é preciso reconhecer que ser profissional, animador, educador ou "líder" de lazer é agir em situações que envolvem as vivências lúdicas, operacionalizando a produção de modos de ser e condutas de diferentes sujeitos, obtendo conhecimentos culturais e vivências que contribuam para qualificar as ações e, ainda, atuar de forma transversal, relacionando-se com as diversas áreas.

\section{REFERÊNCIAS}

ALMEIDA, Ronaldo. Religião na metrópole paulista. Revista Brasileira de Ciências Sociais, v. 19, n. 56, outubro/2004. Disponível em Acesso em: 10 jun. 2017.

ALVES, Cathia. O papel do profissional de Educação Física como intermediário entre o adulto e o lúdico. (Dissertação de mestrado). Faculdade de Ciências da Saúde, Curso de Educação Física, Unimep, 2007.

ALVES, . Propostas de animação para grupos religiosos. In: MARCELLINO, Nelson C. (org). Lazer e Recreação: Repertório de atividades por ambientes vol II. Campinas: Papirus, 2010.

ALVES, As manifestações físico-esportivas de lazer na perspectiva do tempo, atitude e espaço: abordagem da fase de vida adulta e das políticas públicas de lazer. Educação Física em Revista - EFR, v. 7, n. 3, p. 03-18, 2013.

ALVES, Cathia; CÂMARA, Ana Rosa; GERALDIN, Camila; MARTINS, Ida C. Políticas públicas de lazer: jogos, brinquedos e brincadeiras de crianças em praças, na cidade de Araras. Revista Mackenzie de Educação Física e Esporte, São Paulo, v. 13, n. 2, p. 196-214, jul./dez. 2014.

ALVES, Cathia. O lazer no Programa Escola da Família: análise do currículo e da ação dos educadores universitários (Tese de Doutorado). Escola de Educação Física, Fisioterapia e Terapia Ocupacional. Programa de PósGraduação em Estudos do Lazer. Belo Horizonte: UFMG/ EEFTO, 2017.

CAMARGO, Luiz O. L. O lazer e a ludicidade do brasileiro. Revista do centro de pesquisa e formação, maio, 2016.

CAPI, André H. C. Construção de saberes sobre o lazer nas trajetórias de formadores/as do Programa Esporte e Lazer da Cidade (PELC). (Tese de Doutorado). Escola de Educação Física, Fisioterapia e Terapia Ocupacional. Programa de Pós-Graduação em Estudos do Lazer. Belo Horizonte: UFMG/EEFTO, 2016. 
CENSO DEMOGRÁFICO 2010. Características gerais da população, religião e pessoas com deficiência. Rio de Janeiro: IBGE, 2012. Disponível em: <http://biblioteca. ibge.gov.br/visualizacao/periodicos/94/cd_2010_religiao_ deficiencia.pdf>. Acesso em: 10 mai. 2017.

GABRIEL, Oldrey P. Bittencourt; VIEIRA, Lenamar Fiorese. A comunidade adolescente presbiteriana: seus costumes e valores. Revista da Educação Física / UEM, Maringá v. 12, n. 2, 2001.

GABRIEL, Oldrey P. B. Lazer e Religião: algumas aproximações. In: MARCELLINO, Nelson C. Lazer e Sociedade Múltiplas Relações. Campinas: Alínea, 2008a.

GOMES, Christianne L. Lazer: necessidade humana e dimensão da cultura. Revista Brasileira de Estudos do Lazer. Belo Horizonte, v. 1, n.1, p.3-20, jan./abr. 2014.

HUIZINGA, Johan. Homo ludens: o jogo como elemento da cultura. São Paulo: Perspectiva/ EDUSP, 1986.

ISAYAMA, Hélder F. Recreação e Lazer como integrantes de currículos dos cursos de graduação em Educação Física. (Tese de Doutorado) Campinas: Unicamp, Departamento de Educação Física, 2002.

O profissional da Educação Física como intelectual: Atuação no âmbito do lazer. In: MARCELLINO, N, C. Formação e Desenvolvimento de pessoal em lazer e esporte. Campinas: Papirus, 2003.

Educação Física, Recreação e Lazer: considerações a partir dos currículos de formação profissional em Educação Física. In: MOREIRA, W, W (org). Educação Física Intervenção e Conhecimento Científico, Campinas: Unimep, 2004.

Um olhar sobre a formação profissional no lazer. Licere, vol. 8, n.1, p.1-188, Belo Horizonte: UFMG, 2005.

Atuação do Profissional de Educação Física no âmbito do Lazer: a Perspectiva da Animação Cultural. Motriz, Rio Claro, v.15, no p.407-413, abr/jun. 2009.

Formação profissional no âmbito do lazer: desafios e perspectivas. In: Lazer em estudo: Currículo e Formação Profissional. Campinas: Papirus, 2010.

O profissional do lazer. Sinais Sociais. Vol. 8; n. 23. Rio de Janeiro, set-dez, 2013.

MARCELLINO, Nelson C. Lazer e qualidade de vida. In: MOREIRA, Wagner Wey (org). Qualidade de vida: complexidade e educação. Campinas-SP: Papirus, 2001a.

. A ação profissional no lazer, sua especificidade e seu caráter interdisciplinar. In:

(Org.) Lazer: formação e atuação profissional. Campinas: Papirus, 2001b. (org.) Formação e

desenvolvimento de pessoal em lazer e esporte. Campinas: Papirus, 2003.

Campinas: Papirus, 2005.

Pedagogia da Animação. $7^{\mathrm{a}} \mathrm{Ed}$.

Campinas: Papirus, 2008a.

Lazer e Educação. $13^{\circ} \mathrm{Ed}$.

MARCELLINO, Nelson, C. Lazer e Sociedade: algumas aproximações. In: (org). Lazer e Sociedade Múltiplas Relações. Campinas: Alínea, 2008b.

MARCELLINO, Nelson C. CAPI, André, C. SILVA, Debora A. M. Lazer no município: formação e desenvolvimento de quadros - os casos de Campinas e Piracicaba - SP. In: ISAYAMA, Helder. F.; PINTO, Leila, M. S. M. UVINHA, Ricardo, R. STOPPA, Edmur, A. Gestão de politicas de esporte e lazer experiências, inovações, potencialidades e desafios. Belo Horizonte: Ed UFMG, 2011.

MELO, Victor A. A formação cultural do animador cultural: antigas reflexões, persistências, continuidades. In: Lazer em estudo: Currículo e Formação Profissional. Campinas: Papirus, 2010.

MELO, Victor A. O lazer (ou a diversão) e os estudos históricos. In: ISAYAMA, Helder F. SILVA, Silvio R. Estudos do lazer: um panorama. Rio de Janeiro: Apicuri, 2011a.

MELO, Victor A. Sobre lazer, recreação e animação cultural: apontamentos (ou à busca de um espírito). Revista Norte Mineira de Educação Física. Volume 1 Número 1 Ano, 2011b. Disponível em: <file:///C:/Users/Catia/ Downloads/22-63-1-PB.pdf $>$. Acesso 26 de junho, 2016.

MELO, Victor A. Sobre o conceito de lazer. Sinais Sociais. Vol. 8; n. 23. Rio de Janeiro, set-dez, 2013.

PINTO, Leila M. Formação de educadores e educadoras para o lazer: saberes e competências. Rev. Bras. Cienc. Esporte, v. 22, n. 3, p. 53-71, maio 2001.

QUEIROZ, Heitor C, A. CHAVES, Silas F, J. ALVES, Cathia. Formação e intervenção do profissional no lazer: Um estudo de caso de um projeto social no interior do Estado de São Paulo. RENEF, Revista Norte Mineira de Educação Física. vol 06; n. 07, 2016.

RAMOS, Vlademir L. Religião e juventude: entre a felicidade social e a felicidade privada. Estudos de Religião, v. 25, n. 41, 245-252, jul./dez. 2011.

REQUIXA, Renato. O lazer no Brasil. São Paulo: Ed. Brasiliense, 1977.

ROSA, Maria Cristina. Festar na cultura. In ROSA, Maria Cristina (Org.). Festa, lazer e cultura. Campinas, SP: Papirus, 2002, p.11-42. 
SANTOS, Beatriz C. C. A festa de São Gonçalo na viagem em cartas de La Barbinais. In: ANPUH - XXII SIMPÓSIO NACIONAL DE HISTÓRIA, João Pessoa, 2003. Anais eletrônicos... João Pessoa: ANPUH, 2003. Disponível em: $\quad<$ http://anais.anpuh.org/wp-content/uploads/mp/pdf/ ANPUH.S22.089.pdf $>$. Acesso em: 10 jun. 2017.

SANTOS, Carla A. N. L; ISAYAMA, Helder F. O currículo de cursos técnicos de lazer no Brasil: um estudo de caso da formação profissional. Rev. bras. Estud. pedagog. (online), Brasília, v. 95, n. 240, p. 276-303, maio/ago. 2014.

SOARES A. Estilo de vida e hábitos de lazer de líderes religiosos de ambos os sexos. R. bras. Ci. e Mov. 17(3):8395, 2009.

WERNECK, Christianne L. G. A formação profissional no lazer em nossa moderna sociedade: Repensando os limites, os horizontes e os desafios para a área. Revista Licere, Belo Horizonte, v. 1, n.1, p. 47-65, set. 1998.

Lazer, trabalho e educação: Relações históricas, questões contemporâneas. Belo Horizonte: Editora UFMG, 2000.

UNGHERI, Bruno O. A atuação profissional em políticas de esporte e lazer: saberes e competências. Dissertação (Mestrado). 132f. Universidade Federal de Minas Gerais, Escola de Educação Física, Fisioterapia e Terapia Ocupacional, 2014.

WINNICOTT, Donald W. O brincar e a realidade. Rio de Janeiro: Imago, 1975.

Recebido em: 15.06.2017

Aceito em: 21.07.2015 